\title{
Qualidade de tubérculos de batata da cultivar 'Atlantic' afetada pela adubação fosfatada
}

\author{
Quality of potato tubers from cultivar 'Atlantic' as affected by phosphorus fertilization
}

\begin{abstract}
Adalton Mazetti Fernandes ${ }^{\mathrm{I}}$ Rogério Peres Soratto ${ }^{\mathrm{II}}$ Regina Marta Evangelista ${ }^{\mathrm{II}}$
\end{abstract}
\section{RESUMO}

Para avaliar a influência da adubação fosfatada sobre a qualidade dos tubérculos de batata da cultivar 'Atlantic' foram conduzidos experimentos em solos com médio (36 $\left.\mathrm{mg} \mathrm{dm}^{-3}\right)$ $e$ alto $\left(70 \mathrm{mg} \mathrm{dm}^{-3}\right)$ teor de $P$ disponível. Os tratamentos foram constituídos por cinco doses de $\mathrm{P}_{2} \mathrm{O}_{5}(0,125,250,500$ e 1.000

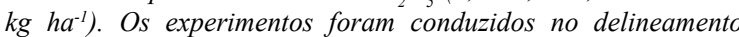
experimental de blocos casualizados, com quatro repetições. Apenas no solo com média disponibilidade de $P$ a adubação fosfatada diminui os teores de proteina, mas aumenta o teor de amido dos tubérculos até a dose de $595 \mathrm{~kg} \mathrm{ha}^{-1}$ de $\mathrm{P}_{2} \mathrm{O}_{5}$. A adubação fosfatada aumenta o tamanho dos tubérculos e a produtividade comercial, porém de forma mais expressiva e até maiores doses em solo com médio teor de P, em que a influência do tamanho do tubérculo sobre a produtividade comercial é maior. Nas duas condições de disponibilidade inicial de P, a adubação fosfatada tem maior influência sobre o tamanho dos tubérculos e a produção de material processado (produtividade de matéria seca de tubérculos), do que sobre as características de qualidade dos tubérculos, que podem influenciar na qualidade da fritura.

Palavras-chave: Solanum tuberosum, produtividade comercial, açúcares redutores, amido, disponibilidade de fósforo.

\section{ABSTRACT}

To evaluate the influence of phosphorus $(P)$ fertilization on the potato tuber quality of the cultivar 'Atlantic' experiments were conducted in soils with medium $\left(36 \mathrm{mg} \mathrm{dm}^{-3}\right)$ and high $(70 \mathrm{mg}$ $\left.d^{-3}\right) P$ availability. The treatments consisted of five $P_{2} O_{5}$ rates $(0$, 125, 250, 500, and 1,000 $\left.\mathrm{kg} \mathrm{ha}^{-1}\right)$. The experiments were conducted in a randomized block design, with four replications. Only in soil with medium $P$ availability, the phosphorus fertilization decreases protein, but increases starch content of the tubers until rate of 595 $\mathrm{kg} \mathrm{ha}^{-1} \mathrm{P}_{2} \mathrm{O}_{5}$. Phosphorus fertilization increases the tuber size and marketable yield, but in a more expressive and until higher rates in soil with medium P concentration, in which the influence of tuber size on marketable yield is higher. In two conditions of $P$ availability, the phosphorus fertilization has greater influence on the tuber size and the production of processed material (dry matter yield of tubers) than on the quality characteristics of tubers that influence in the quality frying.

Key words: Solanum tuberosum, marketable yield, reducing sugars, starch, phosphorus availability.

\section{INTRODUÇÃO}

No Brasil, o consumo de batata (Solanum tuberosum L.) industrializada aumentou nos últimos anos, sendo que a principal cultivar utilizada na indústria de processamento de batata na forma de chips tem sido a cultivar 'Atlantic' (EVANGELISTA et al., 2011). No entanto, o crescimento da indústria de batata processada é dificultado pela falta de tubérculos de maior qualidade e pelo fornecimento irregular dessa matéria-prima por parte dos produtores (QUADROS et al., 2009), tendo em vista que as características dos tubérculos para a indústria de processamento são diferentes daquelas demandadas pelo mercado de consumo in natura. Tubérculos grandes e com formato redondo (PÁDUA, 2010), com elevado peso específico (HOCHMUTH et al., 2002), alta porcentagem de matéria seca (MS) e baixo teor de açúcares redutores (PEREIRA et al., 2007; PÁDUA, 2010) são exigidos pela indústria de chips.

ICentro de Raízes e Amidos Tropicais (CERAT), Universidade Estadual Paulista (UNESP), CP 237, 18610-307, Botucatu, SP, Brasil. E-mail: adalton@cerat.unesp.br. Autor para correspondência.

IIDepartamento de Produção e Melhoramento Vegetal, Faculdade de Ciências Agronômicas (FCA), UNESP, Botucatu, SP, Brasil

IIIDepartamento de Horticultura, FCA, UNESP, Botucatu, SP, Brasil. 
Devido ao fato de a batateira ser considerada como exigente em nutrientes (FERNANDES et al., 2011), na maioria das vezes, essa cultura recebe elevadas doses de fertilizantes, a fim de garantir elevados níveis de produtividade (QUADROS et al., 2009; FERNANDES \& SORATTO, 2012a), muitas vezes, sem se atentar para as características de qualidade dos tubérculos. Entre os fertilizantes utilizados no cultivo da batata, os fosfatados se destacam pelas elevadas doses que são aplicadas no momento do plantio (FERNANDES \& SORATTO, 2012 b) e pelo fato de ser o nutriente que oferece as maiores respostas de produtividade nos solos brasileiros (LUZ et al., 2013).

$\mathrm{O}$ fósforo $(\mathrm{P})$ também pode interferir na qualidade dos tubérculos, tendo em vista que ele atua na síntese do amido e no seu armazenamento nos tubérculos (HOUGHLAND, 1960; ROSEN et al., 2014). Assim, é de se esperar que, numa cultura bem fertilizada com $\mathrm{P}$, os teores de amido sejam maiores e os de açúcares redutores menores, o que é interessante porque altos teores de açúcares redutores causam o escurecimento da batata frita (PEREIRA et al., 2007) e teores mais elevados de amido podem melhorar a qualidade do produto final, por apresentarem influência direta sobre a textura da batata processada (FERNANDES et al., 2010). Estudos também indicam que, em solos deficientes em $\mathrm{P}$, seu fornecimento aumenta o tamanho e o peso específico dos tubérculos (FREEMAN et al., 1998; ROSEN et al., 2014) e, consequentemente, a porcentagem de MS, já que o peso específico é uma forma indireta de estimar a porcentagem de MS dos tubérculos (SCHIPPERS, 1976; ARAUJO, 2014). Porém, alguns estudos demonstraram que, em solos com alta disponibilidade de $\mathrm{P}$, a adubação fosfatada não interfere no peso específico dos tubérculos (HOCHMUTH et al., 2002) e pode até diminuir a produção de tubérculos de maior tamanho (ROSEN \& BIERMAN, 2008). Assim, adubações fosfatadas excessivas podem afetar negativamente as características dos tubérculos, que determinam o padrão de qualidade da batata frita.

Diante disso, o objetivo deste trabalho foi avaliar a influência da adubação fosfatada sobre a qualidade dos tubérculos da cultivar 'Atlantic', em solos com diferentes teores de $\mathrm{P}$ disponível.

\section{MATERIAL E MÉTODOS}

Foram conduzidos dois experimentos no ano de 2011, em áreas de produção de batata, com média (Itaí-SP) e alta (Cerqueira César-SP) disponibilidade de $\mathrm{P}$ (teor de $\mathrm{P}_{\text {(resina) }}$ ). O solo de ambos os locais era Latossolo Vermelho distrófico. Antes da instalação dos experimentos foram coletadas amostras de solo na camada de 0-20cm para determinação das características químicas (RAIJ et al., 2001). Em Itaí, a composição do solo era: matéria orgânica, $26,7 \mathrm{~g} \mathrm{dm}^{-3} ; \mathrm{pH}\left(\mathrm{CaCl}_{2} 0,01\right.$ mol L-1), 4,8; P (resina), 36mg dm ${ }^{-3} ; \mathrm{K}, \mathrm{Ca}, \mathrm{Mg}$ e $\mathrm{H}+\mathrm{Al}$, 2,3, 31, 11 e 46mmol $\mathrm{dm}^{-3}$, respectivamente; e $\mathrm{V}=$ 49\%. Em Cerqueira César, o solo apresentava: matéria orgânica, 27,8g dm${ }^{-3} ; \mathrm{pH}\left(\mathrm{CaCl}_{2}\right.$ 0,01 $\left.\mathrm{mol} \mathrm{L}^{-1}\right), 4,8 ; \mathrm{P}$ (resina), 70mg dm${ }^{-3}$; K, Ca, $\mathrm{Mg}$ e $\mathrm{H}+\mathrm{Al}, 3,3,31,9$ e 51 $\mathrm{mmol}_{\mathrm{c}} \mathrm{dm}^{-3}$, respectivamente; e $\mathrm{V}=46 \%$.

Os experimentos foram conduzidos no delineamento experimental de blocos ao acaso, com quatro repetições. Os tratamentos foram constituídos por cinco doses de $\mathrm{P}_{2} \mathrm{O}_{5}(0,125,250,500$ e $1.000 \mathrm{~kg}$ $\mathrm{ha}^{-1}$ ), utilizando como fonte o superfosfato triplo. Cada parcela foi constituída por cinco fileiras de plantas de $5 \mathrm{~m}$ de comprimento, sendo consideradas como área útil as três fileiras centrais, descartando-se $0,5 \mathrm{~m}$ nas extremidades das fileiras.

Em ambos os experimentos, o preparo do solo foi realizado de forma convencional, com aração e gradagens, e no sulco de plantio foram aplicados $62 \mathrm{~kg} \mathrm{ha}^{-1}$ de $\mathrm{N}$ (sulfato de amônio) e $124 \mathrm{~kg} \mathrm{ha}^{-1}$ de $\mathrm{K}_{2} \mathrm{O}$ (cloreto de potássio). Em 20/04/2011 (Itaí) e 20/05/2011 (Cerqueira César) efetuou-se o plantio da batata, cv. 'Atlantic', no espaçamento de 0,80 x 0,30 $\mathrm{m}$, utilizando tubérculos-semente tipo III (diâmetro de 30 a 50mm) com brotações de cerca de $10 \mathrm{~mm}$ de comprimento. A emergência da cultura ocorreu aos 16 dias após o plantio (DAP), nos dois experimentos. Aos 09 e 12 dias após a emergência (DAE), foi realizada a adubação nitrogenada de cobertura, aplicandose 64 e $41 \mathrm{~kg} \mathrm{ha}^{-1}$ de $\mathrm{N}$, respectivamente, nas áreas com médio e alto teor de $\mathrm{P}$. As doses de $\mathrm{N}$ aplicadas seguiram critérios do produtor e as recomendações de Miranda Filho (1997). Após a adubação nitrogenada de cobertura, foi efetuada a amontoa. Ambos os experimentos foram irrigados por aspersão.

A dessecação da parte aérea da cultura foi realizada aos 79 e 81 DAE nas áreas com média e alta disponibilidade de $\mathrm{P}$, respectivamente. Os tubérculos permaneceram no solo em cura por 21 dias, quando realizou-se a colheita. Os tubérculos colhidos foram lavados e classificados pelo diâmetro transversal, sendo considerados comercializáveis aqueles com diâmetro acima de $23 \mathrm{~mm}$. Em seguida, os tubérculos foram contados e pesados para a determinação da produtividade e da massa média de tubérculos comercializáveis.

Os tubérculos foram pesados no ar e na água, utilizando balança hidrostática de precisão, e 
calculou-se o seu peso específico pela equação: $\mathrm{PE}=$ peso no ar / (peso no ar - peso na água) (KLEINKOPF et al., 1987). Em seguida, os tubérculos foram fatiados manualmente e secos em estufa com circulação forçada de ar à $65^{\circ} \mathrm{C}$ por $96 \mathrm{~h}$ e pesados para a determinação da porcentagem de MS. Com os dados de produtividade comercial e de porcentagem de MS, calculou-se a produtividade de MS de tubérculos, em $\mathrm{kg} \mathrm{ha}^{-1}$. A firmeza foi determinada em três tubérculos (com casca) de cada parcela colhida no campo, utilizando-se texturômetro com profundidade de penetração de $20 \mathrm{~mm}$, velocidade de $2,0 \mathrm{~mm} \mathrm{~s}^{-1}$ e ponteiro TA 9/1000. Os teores de amido e açúcares redutores foram determinados na MS, segundo metodologia descrita por SOMOGYI, adaptada por NELSON (1944), e as leituras realizadas em espectrofotômetro a $535 \mathrm{~nm}$. O teor de proteína foi determinado na MS, com o método de Kjeldahl (método 920.87 da Association of Official Analytical Chemists - AOAC) (HORWITZ \& LATIMER JUNIOR, 2005) e com o fator de 6,25 para conversão em proteína bruta. Em seguida, os dados de amido, açúcares redutores e proteína foram convertidos para teores na matéria fresca.

Os resultados foram submetidos à análise de variância conjunta. As diferenças entre os experimentos, ou seja, entre as disponibilidades de $\mathrm{P}$ no solo, foram separadas pelo teste $\mathrm{t}(\mathrm{DMS})(\mathrm{P}<0,05)$. Os efeitos das doses de $\mathrm{P}$ foram avaliados por análise de regressão. Foram realizadas análises de correlação simples entre as variáveis dependentes, visando determinar o grau de associação entre elas.

\section{RESULTADOS E DISCUSSÃO}

Nas condições de média e alta disponibilidade $\mathrm{P}$ no solo, a produtividade e a massa média dos tubérculos comercializáveis foram similares (Figuras 1a e 1b). A produtividade de tubérculos comercializáveis aumentou em $35 \%$ $(9.420 \mathrm{~kg})$ até a dose estimada de $300 \mathrm{~kg} \mathrm{ha}^{-1}$ de $\mathrm{P}_{2} \mathrm{O}_{5}$, no solo com média disponibilidade de $\mathrm{P}$, enquanto, no solo com alto teor de $\mathrm{P}$, o aumento foi de apenas $24 \%(5.848 \mathrm{~kg})$ e ocorreu apenas até a dose estimada de $125 \mathrm{~kg} \mathrm{ha}^{-1}$ de $\mathrm{P}_{2} \mathrm{O}_{5}$. Isso demonstra que as maiores respostas da batateira ao $\mathrm{P}$ ocorrem em solos com menor disponibilidade inicial desse elemento (FERNANDES \& SORATTO, 2012a). Em solos com baixa disponibilidade de $\mathrm{P}$, outros autores obtiveram aumentos maiores na produtividade de tubérculos, que variaram de 42\% (BOOCK \& FREIRE, 1960; FONTES etal., 1997) a 112\% (ALVAREZ-SÁNCHEZ et al., 1999). Contudo, tanto em solo de baixa como de alta disponibilidade inicial de $\mathrm{P}$, os incrementos na produtividade de tubérculos observados com a aplicação de doses acima de $500 \mathrm{~kg} \mathrm{ha}^{-1}$ de $\mathrm{P}_{2} \mathrm{O}_{5}$ foram pequenos, ou seja, entre 2,5 e 7,0\% (NAVA et al., 2007; LUZ et al., 2013). Neste estudo, a aplicação de doses maiores que $300 \mathrm{~kg} \mathrm{ha}^{-1}$ de $\mathrm{P}_{2} \mathrm{O}_{5}$ não alterou a produtividade de tubérculos comercializáveis nas duas condições de disponibilidade de $\mathrm{P}$ no solo, porque não afetou a massa média de tubérculos (Figuras 1a e 1b). A produtividade de tubérculos comercializáveis correlacionou-se positivamente com a sua massa média, principalmente no solo com médio teor de P (Figura 2a). Isso indica que a adubação fosfatada incrementa a produtividade de tubérculos comercializáveis, por aumentar o tamanho deles e a influência do tamanho do tubérculo sobre a produtividade comercial é maior no solo com média disponibilidade de $\mathrm{P}$.

O peso específico e a porcentagem de MS nos tubérculos não foram afetados significativamente pela adubação e pelo $\mathrm{P}$ inicialmente disponível no solo, mas ambas as variáveis se correlacionaram positivamente nos dois solos (Figuras 1c, 1d e 2b), o que está de acordo com os resultados de SCHIPPERS (1976). Ambas as variáveis têm sido utilizadas como indicador de qualidade dos tubérculos, pois estão relacionadas com a consistência e a textura final das batatas fritas (SCHIPPERS, 1976; ARAUJO, 2014). HOCHMUTH et al. (2002) também não observaram efeito da adubação fosfatada sobre os valores de peso específico dos tubérculos da batateira em solos com teores altos de P. Apesar da adubação fosfatada não ter interferido na porcentagem de MS, ela aumentou a produtividade de tubérculos comercializáveis, o que implica em maior produtividade de MS de tubérculos e maior rendimento de produto processado (batata frita) por área, já que houve alta correlação positiva da produtividade de MS com a produtividade de tubérculos nos dois solos (Figura 2c).

A firmeza dos tubérculos não foi afetada pela disponibilidade inicial de $\mathrm{P}$ nem pela adubação fosfatada (Figura 1e), provavelmente devido ao fato da ausência de efeito dos tratamentos sobre a porcentagem de MS dos tubérculos (Figura 1d). Apesar de não ter sido verificada correlação da firmeza com o peso específico e a porcentagem de MS no presente trabalho (Figura 2d e 2e), pesquisas indicam que a firmeza da polpa de tubérculos de batata se relaciona com o peso específico e com a MS destes, quando estas características variam em função de fatores genéticos ou ambientais (ANZALDÚA-MORALES et al., 1992; EVANGELISTA et al., 2011). 


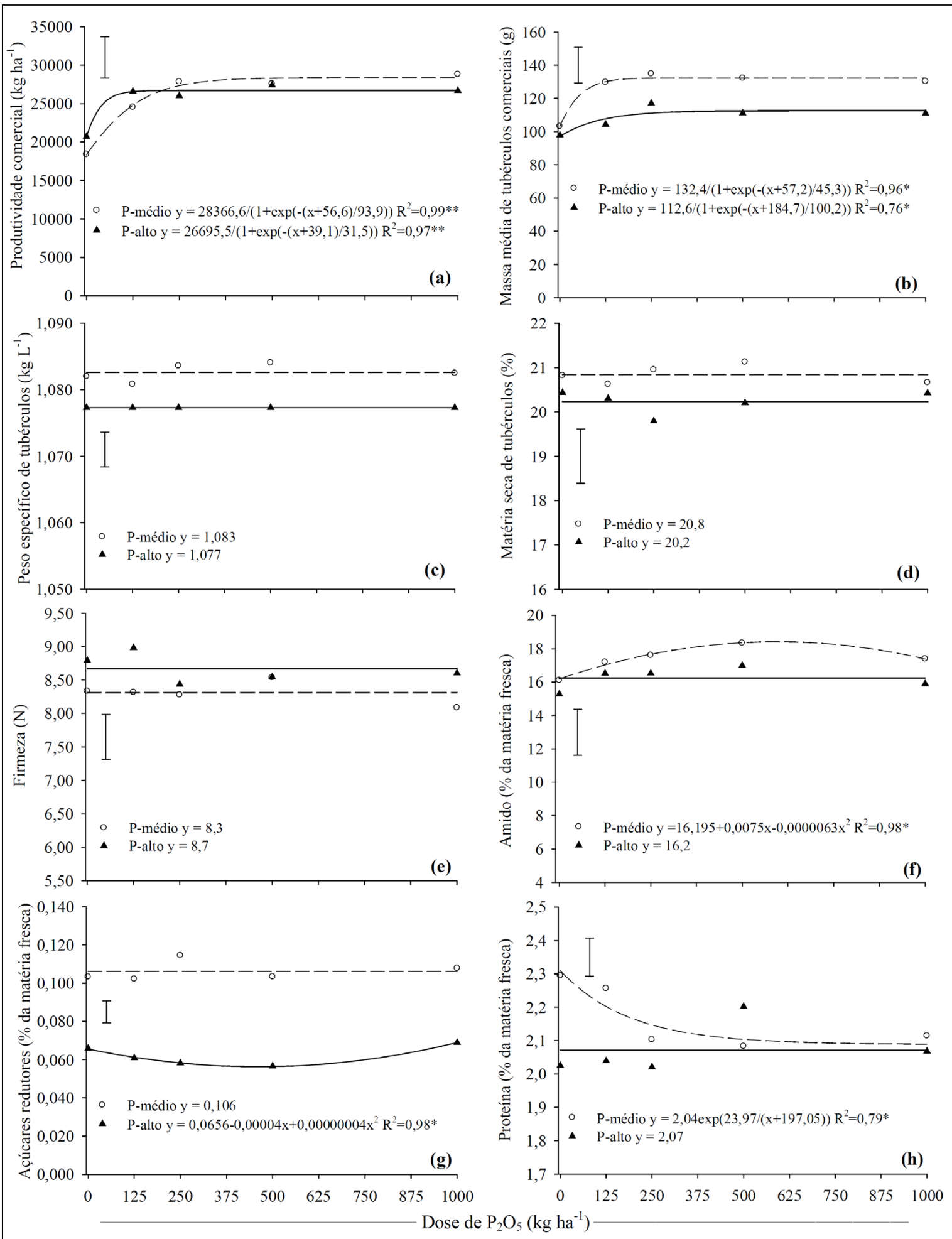

Figura 1 - Produtividade e características de qualidade dos tubérculos comercializáveis da cultivar 'Atlantic', em resposta à adubação fosfatada em solos com média e alta disponibilidade de fósforo. $* \mathrm{P}<0,05$ e ** $\mathrm{P}<0,01$. Barras verticais indicam o valor de DMS pelo teste t (DMS) $(\mathrm{P}<0,05)$. 


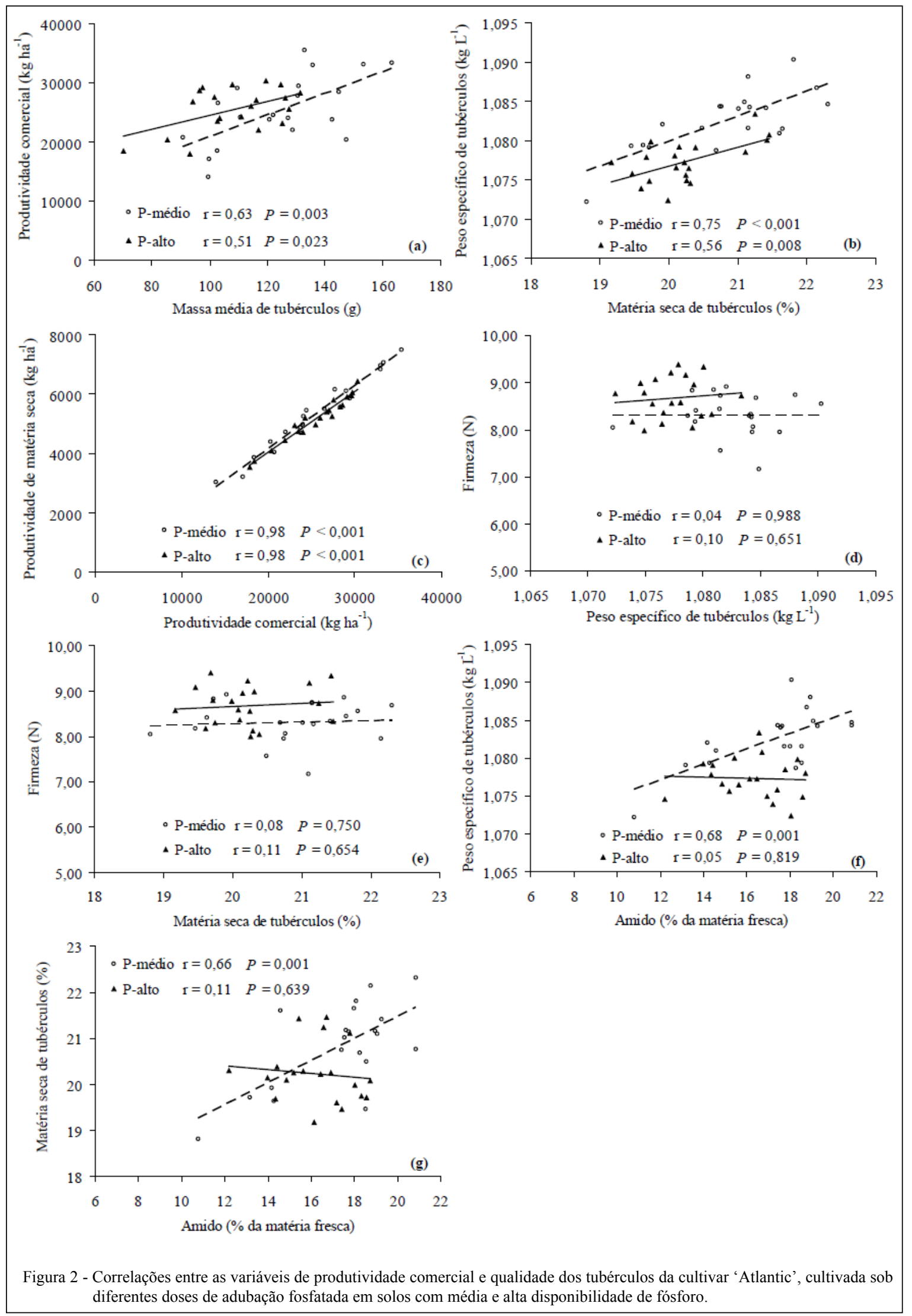

Ciência Rural, v.45, n.8, ago, 2015. 
Apenas na área com médio teor de $\mathrm{P}$ a adubação fosfatada aumentou o teor de amido dos tubérculos em $14 \%$ até a dose estimada de $595 \mathrm{~kg}$ ha $^{-1}$ de $\mathrm{P}_{2} \mathrm{O}_{5}$, mas sem torná-los significativamente maiores que na área com alto teor de $\mathrm{P}$, independentemente da dose de $\mathrm{P}$ aplicada (Figura 1f). Isso demonstra que tanto o $\mathrm{P}$ disponível no solo, quanto o seu fornecimento adequado para as plantas de batata via adubação são importantes para o metabolismo do amido e o desenvolvimento dos tubérculos (HOUGHLAND, 1960; ROSEN et al., 2014). Segundo STARK et al. (2003), a maior disponibilidade de $\mathrm{P}$ tende a aumentar a síntese de amido e acelerar a maturação da planta de batata. Ressalta-se ainda que o teor de amido nos tubérculos correlacionou-se positivamente com o peso específico e a porcentagem de MS destes apenas no solo com médio teor de $\mathrm{P}$ (Figuras $2 \mathrm{f}$ e $2 \mathrm{~g}$ ). Isso indica que há maior influência do peso específico e da porcentagem de MS sobre o teor de amido dos tubérculos apenas em solos com menor disponibilidade desse nutriente. Segundo FERNANDES et al. (2010), tubérculos com maiores teores de amido e, consequentemente, com a polpa mais firme proporcionam produtos processados de melhor textura.

A adubação fosfatada interferiu nos teores de açúcares redutores apenas no solo com alta disponibilidade de $\mathrm{P}$, mesmo assim, de forma pouco expressiva (Figura 1g). Por outro lado, no solo com média disponibilidade de $\mathrm{P}$, os teores de açúcares redutores foram significativamente $(\mathrm{P}<0,05)$ maiores que no solo com alto teor de P disponível. HERLIHY \& CARROLL (1969) verificaram não haver influência da adubação fosfatada sobre o teor de açúcares redutores nos tubérculos da batateira cultivada em solos com baixo teor de P, na Escócia. Altos teores de açúcares redutores causam escurecimento indesejável da batata durante a fritura, reduzindo a aceitação comercial (STARK et al., 2003; FERNANDES et al., 2010). Os resultados indicam que outros fatores, como clima e ponto de maturação dos tubérculos na colheita, podem interferir mais no teor de açúcares redutores nos tubérculos de batata do que a nutrição fosfatada (HERLIHY \& CARROLL, 1969).

O teor de proteína nos tubérculos diminuiu com a adubação fosfatada apenas no solo com média disponibilidade de $\mathrm{P}$ (Figura 1h). Além disso, na ausência da aplicação de P no sulco de plantio, os teores de proteína nos tubérculos foram maiores na área com médio teor de $\mathrm{P}$ disponível. Como a reação de Maillard envolve uma série de passos que se iniciam com a reação entre o grupamento carbonila ou cetona do açúcar redutor e o grupo amino de aminoácidos, peptídeos ou proteínas (LOW et al., 1989), é de se esperar que, em solos com média disponibilidade de $\mathrm{P}$, a redução no teor de proteína dos tubérculos frescos mediante a aplicação de $\mathrm{P}$, possa contribuir para diminuir o escurecimento das batatas durante o processo de fritura.

\section{CONCLUSÃO}

Apenas no solo com média disponibilidade de $\mathrm{P}$, a adubação fosfatada diminui os teores de proteína e aumenta o teor de amido dos tubérculos até a dose de $595 \mathrm{~kg} \mathrm{ha}^{-1}$ de $\mathrm{P}_{2} \mathrm{O}_{5}$.

A adubação fosfatada aumenta o tamanho dos tubérculos e a produtividade comercial, porém de forma mais expressiva e até maiores doses em solo com médio teor inicial de $\mathrm{P}$, no qual a influência do tamanho do tubérculo sobre a produtividade comercial é maior.

Nas duas condições de disponibilidade inicial de $\mathrm{P}$, a adubação fosfatada tem maior influência sobre o tamanho dos tubérculos e a produção de material processado (produtividade de matéria seca de tubérculos) do que sobre as características de qualidade dos tubérculos que podem influenciar a qualidade da fritura.

\section{AGRADECIMENTOS}

À Fundação de Amparo à Pesquisa do Estado de São Paulo (FAPESP) pela concessão de bolsa ao primeiro autor (Proc. 2010/04987-6) e ao Conselho Nacional de Desenvolvimento Científico e Tecnológico $(\mathrm{CNPq})$ pela concessão de auxílio financeiro e bolsa de Produtividade em Pesquisa ao segundo autor.

\section{REFERÊNCIAS}

ALVAREZ-SÁNCHEZ, E. et al. Biomass production and phosphorus accumulation of potato as affected by phosphorus nutrition. Journal of Plant Nutrition, v.22, n.1, p.205-217, 1999. Disponível em: <http://www.tandfonline.com/doi/ pdf/10.1080/01904169909365618\#.VI17KCvF91Q>. Acesso em: 12 dez. 2014. doi: 10.1080/01904169909365618.

ANZALDÚA-MORALES, A. et al. Cultivar, specific gravity and location in tuber affect puncture force of raw potatoes. Journal of Food Science, v.57, n.6, p.1353-1356, 1992. Disponível em: <http:// onlinelibrary.wiley.com/doi/10.1111/j.1365-2621.1992.tb06855.x/pdf $>$. Acesso em: 12 dez. 2014. doi: 10.1111/j.1365-2621.1992.tb06855.x.

ARAUJO, T.H. Produtividade de cultivares de batata e atributos de qualidade para processamento industrial nas formas de palha e chips. 2014. 104f. Dissertação (Mestrado em Fitotecnia) - Curso de Pós-graduação em Fitotecnia, Escola Superior de Agricultura "Luiz de Queiroz", SP.

BOOCK, O.J.; FREIRE, E.S. Adubação da batatinha - experiências com doses crescentes de fósforo. Bragantia, v.19, n.1, p.369-391, 1960. Disponível em: <http://www.scielo.br/scielo.php?pid=S0006- 
$87051960000100025 \&$ script $=$ sci_arttext $>$. Acesso em: 25 maio 2014. doi: 10.1590/S0006-87051960000100025.

EVANGELISTA, R.M. et al. Qualidade nutricional e esverdeamento pós-colheita de tubérculos de cultivares de batata. Pesquisa Agropecuária Brasileira, v.46, n.8, p.953-960, 2011. Disponível em: $<$ http://www.scielo.br/scielo.php?script $=$ sci arttext\&pid=S0100204X2011000800023\&lng=en\&nrm=iso\&tlng=pt>. Acesso em: 05 jun. 2014. doi: 10.1590/S0100-204X2011000800023.

FERNANDES, A.M. et al. Extração e exportação de nutrientes em cultivares de batata: I - Macronutrientes. Revista Brasileira de Ciência do Solo, v.35, n.6, p.2039-2056, 2011. Disponível em: $<$ http://www.scielo.br/scielo.php?script=sci_arttext\&pid=S0100$06832011000600020 \& \operatorname{lng}=\mathrm{pt \& nrm}=\mathrm{iso}>$. Acesso em: 06 jun. 2014. doi: 10.1590/S0100-06832011000600020.

FERNANDES, A.M. et al. Qualidade físico-química e de fritura de tubérculos de cultivares de batata na safra de inverno. Horticultura Brasileira, v.28, n.3, p.299-304, 2010. Disponível em: <http:// www.scielo.br/scielo.php? script $=$ sci_arttext\&pid $=\mathrm{S} 0102-$ $05362010000300010 \& \operatorname{lng}=$ pt\&nrm $=$ iso $>$. Acesso em: 05 jun. 2014. doi: 10.1590/S0102-05362010000300010.

FERNANDES, A.M.; SORATTO, R.P. Nutrição mineral, calagem e adubação da batateira. Botucatu/Itapetininga: FEPAF/ ABBA, 2012a. 121p.

FERNANDES, A.M.; SORATTO, R.P. Nutrition, dry matter accumulation and partitioning, and phosphorus use efficiency of potato plants grown under phosphorus rates in nutrient solution. Revista Brasileira de Ciência do Solo, v.36, n.5, p.1528 - 1537, 2012b. Disponível em: $<$ http://www.scielo.br/scielo.php?script=sci arttext\&pid=S0100-06832012000500017\&lng=pt\&nrm=iso $>$. Acesso em: 04 jun. 2014. doi: 10.1590/S0100-06832012000500017.

FONTES, P.C.R. et al. Produção máxima e eficiência de econômica da batata em função da adubação fosfatada. Horticultura Brasileira, v.15, p.104-107, 1997.

FREEMAN, K.L. et al. Effect of phosphorus on the yield, quality and petiolar phosphorus concentrations of potatoes (cv. 'Russet Burbank' and 'Kennebec') grown in the krasnozem and duplex soils of Victoria. Australian Journal of Experimental Agriculture, v.38, n.1, p.83-93, 1998. Disponível em: <http://www.publish.csiro.au/paper/EA96045. htm>. Acesso em: 07 jun. 2014. doi: 10.1071/EA96045.

HERLIHY, M.; CARROLL, P.J. Effects of N, P and $\mathrm{K}$ and their interactions on yield, tuber blight and quality of potatoes. Journal of the Science of Food and Agriculture, v.20, 513-517, 1969. Disponível em: <http://onlinelibrary.wiley.com/doi/10.1002/jsfa.2740200901/ pdf $>$. Acesso em: 07 ago. 2014. doi: 10.1002/jsfa. 2740200901.

HOCHMUTH, G. et al. Potato yield and tuber quality did not respond to phosphorus fertilization of soil testing high in phosphorus content. HorTechnology, v.12, n.3, p.420-422, 2002. Disponível em: <http:/horttech. ashspublications.org/content/12/3/420.full.pdf $>$. Acesso em: 08 ago. 2014.

HORWITZ, W.; LATIMER JUNIOR, G.W. Official methods of analysis of the Association of Analytical Chemists International. 18 ed. Gaythersburg: AOAC International, 2005. 114p.

HOUGHLAND, G.V.C. The influence of phosphorus on the growth and physiology of the potato plant. American Potato Journal, v.37, n.4, p.127-138, 1960. Disponível em: < http://link.springer. com/article/10.1007\%2FBF02855950>. Acesso em: 05 jun. 2014 doi: $10.1007 / \mathrm{BF} 02855950$.
KLEINKOPF, G.E. et al. Specific gravity of Russet Burbank potatoes. American Potato Journal, v.64, n.11, p.579-587, 1987.

LOW, N. et al. Redution of glucose content in potatoes with glucose oxidase. Journal of Food Science, v.54, n.1, p.118121, 1989. Disponível em: <http://onlinelibrary.wiley.com/ doi/10.1111/j.1365-2621.1989.tb08581.x/abstract $>$. Acesso em: 22 maio 2014. doi: 10.1111/j.1365-2621.1989.tb08581.x.

LUZ, J.M.Q. et al. Influence of phosphate fertilization on phosphorus levels in foliage and tuber yield of the potato cv. 'Ágata'. Semina: Ciências Agrárias, v.34, n.2, p.649-656, 2013. Disponível em: $<$ http:// www.uel.br/revistas/uel/index.php/semagrarias/article/view/11497>. Acesso em: 04 jun. 2014. doi: 10.5433/1679-0359.2013v34n2p649.

MIRANDA FILHO, H.S. Batata. In: RAIJ, B. van. et al. (Eds.) Recomendações de adubação e calagem para o Estado de São Paulo. Campinas: Instituto Agronômico de Campinas, 1997. p.225. (Boletim Técnico, 100).

NAVA, G. et al. Produção de tubérculos de batata-semente em função das adubações nitrogenada, fosfatada e potássica. Horticultura Brasileira, v.25, n.3, p.365-370. 2007. Disponível em: <http:// www.scielo.br/scielo.php? script $=$ sci_arttext\&pid $=\mathrm{S} 0102$ $05362007000300009 \& \operatorname{lng}=$ pt\&nrm $=$ iso $>$. Acesso em: 18 maio 2014. doi: 10.1590/S0102-05362007000300009.

NELSON, N.A. A photometric adaptation of Somogy method for determination of glucose. Journal of Biological Chemistry, v.153, n.1, p.375-390, 1944.

PÁDUA, J.G. Produção de batata e mandioquinha-salsa visando o processamento industrial. Revista Raízes e Amidos Tropicais, v.6, n.1, p.147-161, 2010. <http://energia.fca.unesp.br/index.php/ rat/article/view/1115/462>. Acesso em: 17 out. 2014.

PEREIRA, A.S. et al. Genótipos de batata com baixo teor de açúcares redutores. Horticultura Brasileira. v.25, n.2, p.220-223, 2007. Disponível em: <http://www.scielo.br/pdf/hb/v25n2/17. pdf $>$. Acesso em: 07 jun. 2014.

QUADROS, D.A. et al. Composição química de tubérculos de batata para processamento, cultivados sob diferentes doses e fontes de potássio. Ciência e Tecnologia de Alimentos, v.29, n.2, p.316-323, 2009. Disponível em: $<\mathrm{http}: / /$ www.scielo.br/scielo.php?script=sci arttext\&pid $=$ S0101-20612009000200013\&lng =pt\&nrm $=$ iso $>$. Acesso em: 07 jun. 2014. doi: 10.1590/S0101-20612009000200013.

RAIJ, B. van. et al. Análise química para avaliação da fertilidade de solos tropicais. Campinas: Instituto Agronômico, 2001. 284p.

ROSEN, C.J. et al. Optimizing Phosphorus Fertilizer Management in Potato Production. American Journal of Potato Research, v.91, n.2, p.145-160, 2014. Disponível em: < http://link.springer. com/article/10.1007\%2Fs12230-014-9371-2>. Acesso em: 07 jun. 2014. doi:10.1007/s12230-014-9371-2.

ROSEN, C.J.; BIERMAN, P.M. Potato yield and tuber set as affected by phosphorus fertilization. American Journal of Potato Research, v.85, n.2, p.110-120, 2008. Disponível em: <http://link. springer.com/article/10.1007/s12230-008-9001-y>. Acesso em: 13 ago. 2014. doi: 10.1007/s12230-008-9001-y.

SCHIPPERS, P.A. The relatioship between specific gravity and percentage of dry matter in potato tubers. American Potato Journal, v.53, n.4, p.111-122, 1976

STARK, J.C. et al. Tuber quality. In: STARK J.C.; LOVE S.L. Potato production systems. Aberdeen: University of Idaho, 2003. p.329-343. 